\title{
SUSTAINABLE GREEN INFORMATION SYSTEMS DESIGN: A THEORETICAL MODEL
}

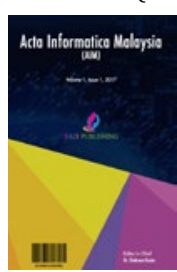

\author{
Shireen Muhammad ${ }^{1 *}$, Yusmadi Yah Jusoh ${ }^{2}$, Jamilah Din $^{2}$, Rozi Nor Haizan Nor ${ }^{2}$, Shamala Palaniappan ${ }^{3}$ \\ ${ }^{1}$ Faculty of Communication, Visual Art and Computing, Universiti Selangor, Malaysia \\ ${ }^{2}$ Faculty of Computer Science and Information Technology, Universiti Putra Malaysia, Malaysia \\ ${ }^{3}$ Soft Computing and Data Mining Centre, Faculty of Computer Science and Information Technology, Universiti Tun Hussein Onn, \\ Johor, Malaysia \\ *Corresponding author email: shireen@unisel.edu.my
}

This is an open access article distributed under the Creative Commons Attribution License, which permits unrestricted use, distribution, and reproduction in any medium, provided the original work is properly cited.

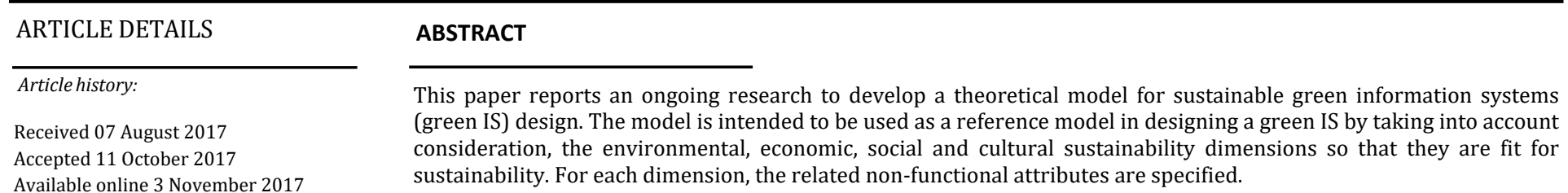

Keywords:

Sustainable design, green IS

\section{INTRODUCTION}

The roles of IS in sustainable development is an interesting topic in green IS. While IS will be a major element in the transition to a sustainable economy, it is believed that the greening efforts would be played and better assisted specifically by green IS through inscribing green values in the spirit of an IS at the time of design and development [1-3]. At present, there is a strong call for research action in designing green IS with broader perspective by integrating sustainability dimensions and building green IS for sustainability $[4,5]$. Sustainable development takes into account the environmental, economic and social impacts consideration in meeting the needs of humans. However, to view sustainability from these three dimensions alone are no longer reflect the complexity of current global society of multination that interact and integrate in an open and borderless digital world [6,7]. Accordingly, as suggested by some researcher, culture is added as the fourth pillar of sustainability [7]. The environmental, economic, social and cultural dimensions will hence form a holistic perspective of present-day sustainability.

\section{METHODOLOGY}

The theoretical model is derived from literatures. Particularly for the environmental dimension as the primary dimension for this study, the review is mainly conducted based on the "light" version of systematic review as proposed by a group researcher with snowballing approach to complement database search [8-11]. Relevant articles for green IS design framework were mainly selected by referring to the Association of Information Systems (AIS) and thus, are relevant to the IS academic community. Literatures were managed with the assistance of Microsoft Excel and Endnote reference manager.

\section{FINDINGS}

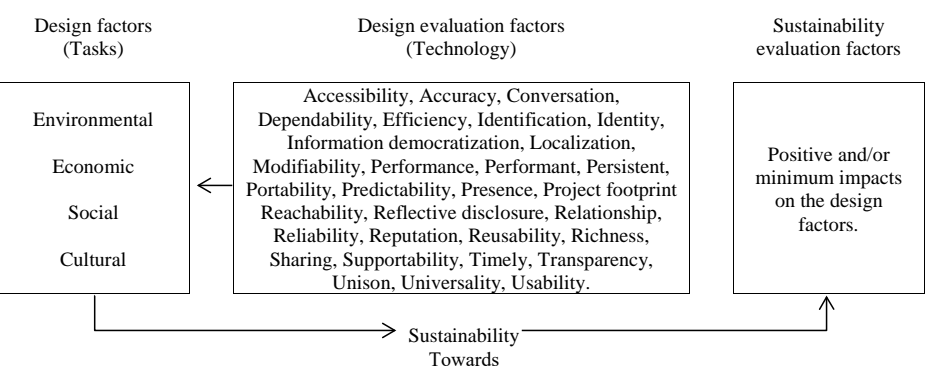

Figure 1: Sustainable Green IS Design Model - SGISDM - a theoretical model
The review has found that although researchers have started to consider green IS design, the overall body of research lack of study on integrated model for general class of green IS [8]. Furthermore, as noted in Section 1., recent development in green IS research is directing towards sustainability objective. This research is thus motivated to incorporate holistic sustainability perspective into green IS design endeavor that is translated into a theoretical model depicted in Figure 1 - the Sustainable Green IS Design Model (SGISDM).

The primary purpose of SGISDM is to assist green IS designers in identifying the non-functional attributes required for a general green IS that are aligned with the aim of sustainability. As mentioned earlier, the factors to be considered during designing such systems not only environmental, but also economic, social and cultural in which, each dimension are further extended into its relevant evaluation factors. Finally, alignment with the sustainability aim will be evaluated by adopting the Task-Technology Fit (TTF) model [12, 13].

\section{CONCLUSION}

Sustainability has become a major non-functional requirement for green IS and needs to be taken into account during the earliest design phase. This is aligned with the 'Green as The Spirit of IS' paradigm adopted from some study, in which attention should be given during the design and development processes. However, it is not a simple situation to design such systems that is aligned between all sustainability concerns and end-users' expectations. This research regards this as an opportunity in assisting green IS designers in realising their end-users' expectations based on the nonfunctional requirements, from the lens of sustainability.

\section{REFERENCES}

[1] Esty, D.C., and Andrew, S. 2009. Green to gold: How smart companies use environmentalstrategy to innovate, create value, and build competitive advantage. John Wiley \& Sons.

[2] Watson, R.T., Boudreau, M.C., and Chen, A.J. 2010. Information systems and environmentally sustainable development: energy informatics and new directions for the IS community. Management Information Systems Quarterly, 34 (1), 23-38.

[3] Ijab, M.T., Molla, A., Kassahun, A.E., Teoh, S.Y. 2010. Seeking the "Green" in "Green IS": A spirit, practice and impact perspective. PACIS 2010 Proceedings, 46.

[4] Seidel, S., Bharati, P., Fridgen, G., Watson, R.T., Albizri, A., Claude, M., Boudreau, Butler, T., Kruse, L.C., Guzman, I., Karsten, H., Lee, H., Melville, N., Rush, D., Toland, J., and Watts, S. 2017. The sustainability imperative in 
information systems research.Communications of the Association for Information Systems, 40 (1), 40-52.

[5] Watson, R.T., Boudreau, M.C., Chen, A.J., Sepúlveda, H.H. 2011. Green projects: Aninformation drives analysis of four cases. The Journal of Strategic Information Systems, 20(1), 55-62.

[6] Cities, U., and Governments, L. 2010. Culture: Fourth pillar of sustainable development.United Cities and Local Governments (UCLG) Policy Statement.

[7] York, T.L.I.-T.S.U.o.N. 2016. What Is Globalization? The Levin Institute The StateUniversity of New York.

[8] Shireen, M., Yah, J.Y., Jamilah, D., Haizan, N.R.N. 2017. Green Information SystemsDesign Framework: a Systematic Literature Review. Journal of Theoretical and AppliedInformation Technology, 95 (6), 1338-1346.

[9] Keele, S. 2007. Guidelines for performing systematic literature reviews in softwareengineering. Technical report, EBSE Technical Report EBSE-2007-01.

[10] Stapić, Z., Lopez, E.G., Luis de Marcos Ortega, A.G.C., Strahouja, V. 2012. Performingsystematic literature review in software engineering. Proceedings of the Central EuropeanConference on Information and Intelligent Systems, 441-493.

[11] Wohlin, C. 2014. Guidelines for Snowballing in Systematic Literature Studies and aReplication in Software Engineering. Proceedings of the 18th international conference onevaluation and assessment in software engineering, 38.

[12] Goodhue, D.L. 1998. Development and measurement validity of a task-technology fitinstrument for user evaluations of information system. Decision Sciences, 29 (1),105-138.

[13] Goodhue, D.L., and Thompson, R.L. 1995. Task-technology fit and individualperformance. MIS quarterly, 213-236. loud computing. 